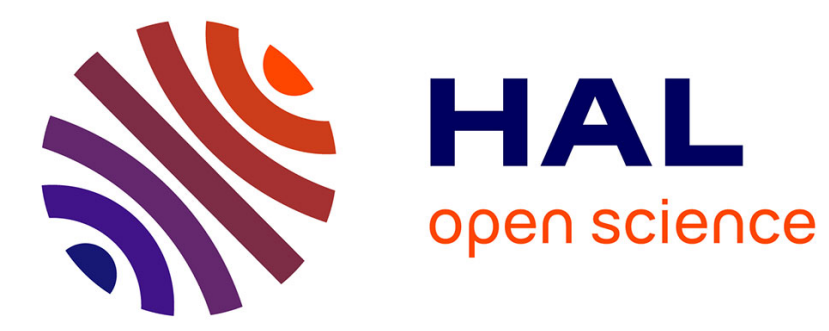

\title{
Dust particles in low-pressure plasmas: Formation and induced phenomena
}

Maxime Mikikian, Marjorie Cavarroc, Lénaïc Couëdel, Yves Tessier, Laifa Boufendi

\section{- To cite this version:}

Maxime Mikikian, Marjorie Cavarroc, Lénaïc Couëdel, Yves Tessier, Laifa Boufendi. Dust particles in low-pressure plasmas: Formation and induced phenomena. Pure and Applied Chemistry, 2010, 82, pp.1273. 10.1351/PAC-CON-09-10-30 . hal-00486477

\section{HAL Id: hal-00486477 \\ https://hal.science/hal-00486477}

Submitted on 25 May 2010

HAL is a multi-disciplinary open access archive for the deposit and dissemination of scientific research documents, whether they are published or not. The documents may come from teaching and research institutions in France or abroad, or from public or private research centers.
L'archive ouverte pluridisciplinaire HAL, est destinée au dépôt et à la diffusion de documents scientifiques de niveau recherche, publiés ou non, émanant des établissements d'enseignement et de recherche français ou étrangers, des laboratoires publics ou privés. 
Pure Appl. Chem., Vol. 82, No. 6, pp. 1273-1282, 2010.

doi:10.1351/PAC-CON-09-10-30

(C) 2010 IUPAC, Publication date (Web): 14 April 2010

\title{
Dust particles in low-pressure plasmas: Formation and induced phenomena*
}

\author{
Maxime Mikikian $\ddagger$, Marjorie Cavarroc ${ }^{\star \star}$, Lénaïc Couëdel ${ }^{\dagger}$, \\ Yves Tessier, and Laïfa Boufendi
}

\author{
GREMI, UMR6606 CNRS/Université d'Orléans, 14 rue d'Issoudun, BP6744, 45067 \\ Orléans Cedex 2, France
}

\begin{abstract}
Formation of dust particles is a common mechanism in low-pressure plasmas. These big particles (in comparison with other plasma species) are sometimes the desired final products of the process, but they may also constitute a severe drawback in certain contexts. In either situation, it is necessary to understand growth mechanisms well, in order to control or avoid dust particle formation. One of the problems that has to be overcome is that dust particle growth is usually a continuous mechanism: once started, it can enter into a cyclic regime where new generations of dust particles are succeeding one after the other. This cyclic phenomenon often induces a side effect consisting of instabilities of a few tens of $\mathrm{Hz}$. This paper discusses the main characteristics of dust successive generations, and particularly the importance of dust-free spaces (void) involved in this process. Finally, some aspects related to deposition when several generations coexist will be presented.
\end{abstract}

Keywords: complex plasmas; deposition; dust particle formation; dusty plasmas; instabilities; nanoparticles; silane; void.

\section{INTRODUCTION}

In addition to electrons, ions, atoms, and molecules, plasmas very often contain solid dust particles with sizes ranging from a few nanometers to centimeters [1]. The presence of this additional species is at the origin of a wide variety of new plasma phenomena. Those plasmas containing dust particles constitute a highly interdisciplinary field of research called dusty (or complex) plasmas. These media are encountered in many environments such as astrophysics [2-4], industrial processes [5-7], and fusion devices [8-10]. Dusty plasmas are due to the simultaneous presence in the same place of dust particles and plasmas, but a noteworthy aspect is that dust particles can be formed in the plasma itself. In this last case, the fundamental requirement is the presence of molecular precursors [11]. These precursors result from the presence of reactive gases (silane $\mathrm{SiH}_{4}$ [5,12-16], methane $\mathrm{CH}_{4}$ [17-19], acetylene $\mathrm{C}_{2} \mathrm{H}_{2}$ $[17,20,21]$ ) or from material erosion (physical or chemical) at the molecular level [22-26]. They initiate a complex succession of chemical and physical reactions, leading to the growth of dust particles. As long as those precursors are available in the plasma phase, dust particle formation can be a cyclic phenomenon [16,25,27-29].

As dust particles are growing, they attach plasma-free electrons [30-34], leading to a disturbance of the plasma equilibrium when the dust particle density is high. New phenomena, like the occurrence

\footnotetext{
*Paper based on a presentation at the $19^{\text {th }}$ International Symposium on Plasma Chemistry (ISPC-19), 26-31 July 2009, Bochum, Germany. Other presentations are published in this issue, pp. 1189-1351.

¥Corresponding author: E-mail: maxime.mikikian@univ-orleans.fr

**Current address: Made In Dreux, 4 rue Albert Caquot, 28500 Vernouillet, France

${ }^{\dagger}$ Current address: Max-Planck-Institut für Extraterrestrische Physik, Giessenbachstrasse, 85741 Garching, Germany
} 
of various instabilities, are then observed [16,24,35-38]. These behaviors appear in many dusty plasmas created in different chemistries, experimental set-ups, or conditions, and it is thus possible to suggest that they can be considered as universal characteristics of dusty plasmas. A good understanding of these aspects requires a fine knowledge of dust particle growth kinetics, charging phenomena, and plasma-dust interaction. Laboratory research on these aspects is fundamental to understand dust particle formation and behavior in astrophysical environments, industry, and fusion. In thermonuclear fusion, dust particle formation due to wall erosion is obviously a negative aspect as it affects the plasma stability. It also raises the question of safe dust removal due to dust's ability to retain radioactive elements such as tritium. In the industry, and particularly in microelectronics, dust formation is also a phenomenon to avoid (or at least to control). Due to the constant miniaturization of electronic components that reach nanometer sizes, dust particles of only a few tens of nanometers become "killer" particles damaging the device. On the contrary, this race toward miniaturization opens very promising perspectives for dusty plasmas. Indeed, they are very efficient tools for building nanometer-scale objects for applications related to nanotechnologies or nanostructured materials. In this context, much research is performed in order to control the formation and deposition of nanocrystals $[28,39,40]$.

In this paper, the cyclic behavior of dust particle formation is analyzed. In a first part we show that, in a plasma containing dust particles, new dust generations can appear in specific dust-free regions. This process can be followed thanks to several diagnostics such as video imaging or measurements of the discharge characteristics. A second part studies complex low-frequency instabilities related to the growth kinetics of dust successive generations. Finally, a last part addresses the consequences of a deposition performed when a cloud containing several dust particle generations is trapped in the plasma.

To analyze these aspects, experiments are performed in capacitively coupled radio-frequency (RF) discharges where dust particles are grown either in silane/argon mixtures (silane reactor) [39] or by using an argon plasma to sputter a polymer layer deposited on the electrodes (PKE-Nefedov reactor) [25]. These two experiments differ by their geometry, the typical injected RF power (from 2 to $20 \mathrm{~W}$ ), and the gas pressure (from 0.1 to 2 mbar). Despite their many differences, particularly in the way to grow dust particles, it appears that most of the observed phenomena are qualitatively similar. This is a crucial point of this work and a quite reliable indication that the following aspects have certainly a universal character in dusty plasma physics.

\section{DUST SUCCESSIVE GENERATIONS RELATED TO DUST-FREE SPACES}

Formation of dust particles has been widely studied, especially in silane-based chemistry, for controlling, avoiding, or improving the growth of dust particles. Due to the concerned applications, these studies mainly focused on the growth of the first dust particle generation. Since then, some works related to the formation of dust successive generations have been performed [11,16,19,25,27-29]. These successive generations of dust particles are observed as long as precursors are formed in the plasma phase, and consequently a continuous feeding of reactive gases or a continuous sputtering is necessary. Furthermore, the plasma characteristics (especially the free electron population) must allow precursor formation and dust particle growth. Due to the previous dust particle generation, plasma conditions for dust particle formation can have changed or some inhibiting effects can have arisen. It is, for example, the case in $\mathrm{CH}_{4}$-based plasmas [18,27,41]. It appears that conditions for the growth of new generations of dust particles are fulfilled in dust-free spaces existing in the discharge volume. One of these regions appears close to the center of dust clouds and is named the "void" [25,42-44].

\section{In a sputtering discharge}

The process of dust successive generation has been clearly observed in the PKE-Nefedov reactor [25], which is optimized for imaging dust particle clouds. Once the first dust particle generation has been grown and dust particles have reached a sufficiently big size (for ion drag to be efficient), a dust-free 

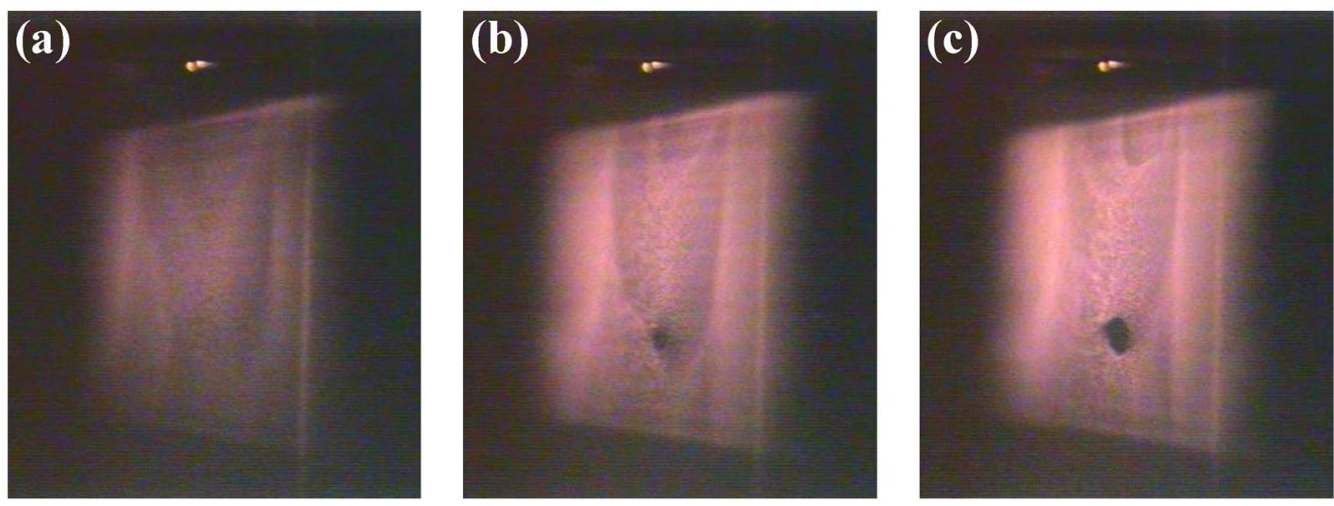

Fig. 1 Appearence of a void in the center of a dust cloud. Dust particles are growing from (a) to (c), the size in (c) is about a few hundreds nm. The view angle is about $20^{\circ}$ with respect to the laser direction.

space (void) appears in the center of the dust cloud [25,42-44]. This effect is well observed in Figs. 1a-c where a void appears progressively as dust particles become bigger. It should be noted that for a given dust particle size, increasing the power or decreasing the pressure can also lead to a void opening.

The void is a singular structure sustained through an equilibrium between an inward electrostatic force and an outward ion drag force [42]. The void is at the origin of many complex phenomena like some spectacular instabilities $[43,45]$. Inside the void, it appears that dust formation conditions are fulfilled while they seem to be inhibited in the surrounding dense dust cloud. A new dust generation can start its growth inside the void and, while growing, favors the expulsion of the previous generation by pushing away older dust particles. This process can become cyclic: as soon as the new dust particles reach a sufficiently big size, a new void is formed and the scenario starts again [25]. This process leads to the coexistence of various dust particle populations in the plasma. A typical example is given in Fig. 2 where three different generations are observed with a new void emerging from the most recent generation. The first suggestion that can be proposed from Fig. 2 is that new generations of dust particles arise from dust-free spaces where local conditions are favorable and could be close to the ones of the plasma just after its ignition when the first dust particle generation started to grow.

The second point that can be underlined from Fig. 2 is the well-defined boundaries between the successive dust clouds. This observation is strengthened by the existence of a clear sheath separating two successive generations. The new growing cloud pushes away the previous one through electrostatic interactions. It involves a specific distance of interaction that can have a typical length of the order of the observed sheath width. Thus, at this stage the two generations cannot be mixed (like immiscible fluids). These two combined phenomena mean that the two clouds interact as two "solid" homogeneous bodies. The discrete interactions between dust particles from one cloud and those from the other cloud are nearly not detectable.

The last effect that can be deduced from these experiments is related to dust particle segregation. Usually, the global forces acting on dust particles tend to push the bigger dust particles toward the external parts of the cloud. In other words, in a multicomponent system it is expected to have the smaller dust particles in the inner part of the cloud and the bigger ones in the outer parts. In Fig. 2, the reverse situation is observed due to the strong electrostatic interaction between the different generations. Indeed, the new dust particles cannot escape from their inner position because they are confined and trapped by the surrounding older generation. Thus, the new generation can continue its growth and even reach sizes bigger than the old generation. This phenomenon can be observed when the growth kinetics is quite slow as in those experiments where the growth of successive generations is not a predominant effect. If it was the case, the new generation would have never been able to become so big because 

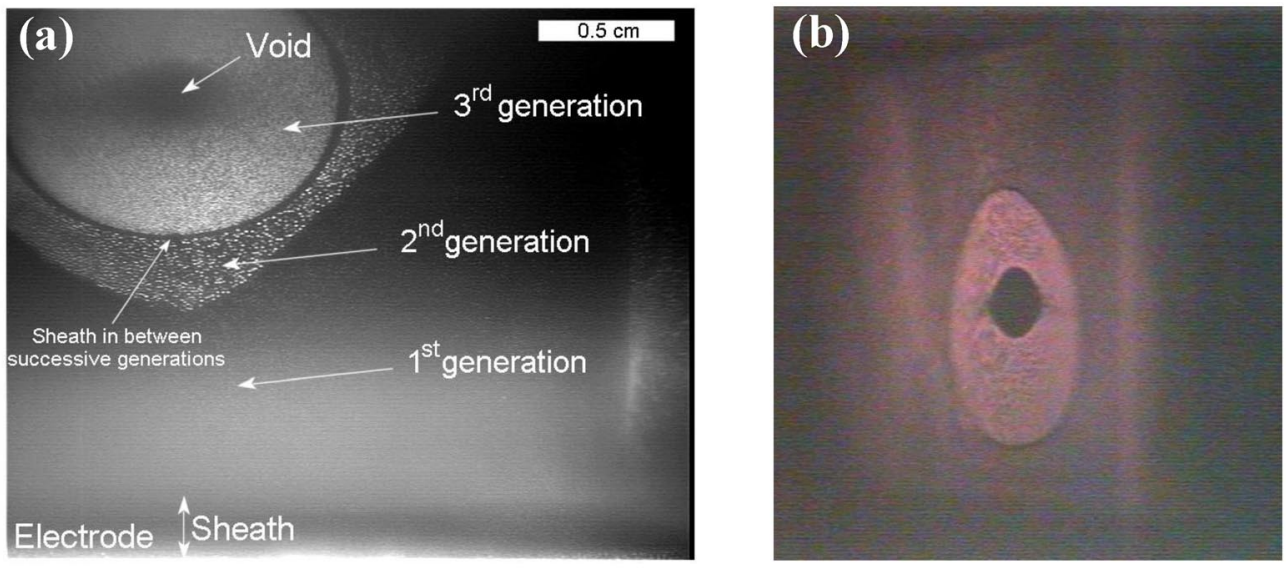

Fig. 2 Successive generations of dust particles born from the void. A clear sheath structure can be observed between the successive generations. (a) case with three generations, image taken with the camera at $90^{\circ}$ with respect to laser direction, (b) case with two generations, image taken with the camera at around $20^{\circ}$ with respect to laser direction.

it would have been pushed away by the growth of another generation. When gravity becomes too strong, the electrostatic trapping is no more sufficient: the recent generation succeeds in going through the previous dust generation to finally reach the lower layers close to the bottom electrode. Some of these gravitational effects are observed in Figs. 2a,b where the new cloud is not homogeneously distributed around the void. A "droplet" shape can be observed with more dust particles at the bottom of the cloud. A few seconds later, dust particles from the new cloud become too big, and start to move toward the lower electrode.

\section{In a silane-based discharge}

In the silane discharge where the dust growth kinetics is fast and the feeding of precursors much more continuous, we tried to observe if the growth of dust successive generations follows a quite similar cycle, i.e., if the formation of new generations takes place in the void. The problem to overcome is that this reactor has been designed to be close to industrial systems, meaning that only small optical accesses are available. Thus, the challenge was to check if a quite similar conclusion can be drawn thanks to indirect measurements. This work has been reported precisely in a recent paper [16]. The conclusion that results from this analysis is that in silane-based discharges the growth of dust successive generations follows a similar cycle to the one observed in the sputtering discharge and analyzed in the previous section. Once again, the void plays a major role in the growth cycle. As the same effect has been also highly suspected in acetylene discharge [27], it is thus quite reasonable to assume that new generations of dust particles originate from the void, the central dust-free space. This behavior has been also suggested by recent simulations [29].

Concerning the silane-based discharge, as optical accesses are limited, successive generations have to be detected thanks to indirect measurements. As reported in [16], it is quite difficult to deduce the spatiotemporal evolution of dust particle successive generations from only one measurement. Now that this evolution has been attested, it could be interesting to take the problem in a reverse way and use the conclusion (dust successive generations arise from the void) to understand better some isolated measurements. For this analysis, the evolution of the amplitude of the third harmonics of the discharge current is used as a reference (Fig. 3). 


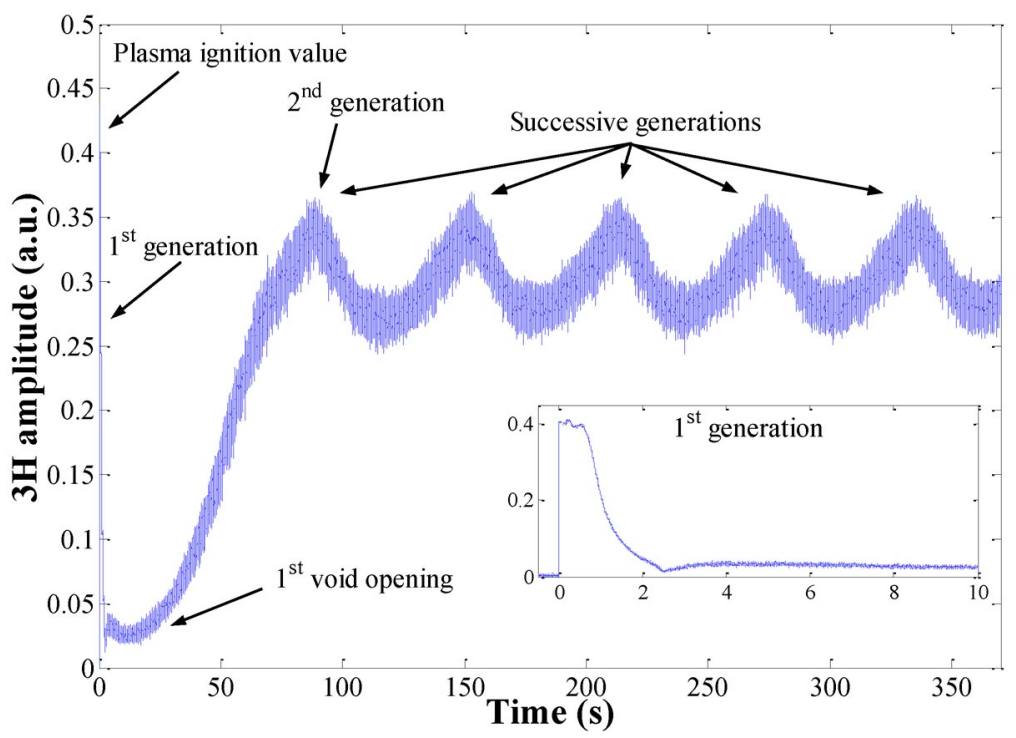

Fig. 3 Evidence of dust successive generations on electrical measurements. Each new generation corresponds to a bump in the signal. The first generation (see zoom in the insert) differs from the others because it originated from a plasma entirely free of dust particles.

As observed in Fig. 3, the indication that successive generations appear is a very low frequency modulation of the signal with a typical period of about $1 \mathrm{~min}$. This oscillation in electrical measurements (also observed in optical measurements) is due to the appearance of dust successive generations and has been observed by several authors in silane $[16,28,46]$ or hydrocarbon-based plasmas $[18,41]$. In the case presented in Fig. 3, the successive generations differ from the first generation but are then identical (at least during the observed time duration). However, it is not always the case. As an example, a damping of this oscillation has been reported in acetylene, meaning that the formation or the growth are partially inhibited, or that the dust particles are removed from the plasma due to the presence of evolving detrapping forces [18,41]. On the contrary, the case presented in Fig. 3 suggests that a well-established equilibrium is reached between the formation of new dust particles and the loss of dust particles from older generations.

It is also significant that the evolution of the signal for these successive generations does not reproduce the evolution observed for the first generation (Fig. 3 insert). It means that the dust-free plasma conditions existing just after the plasma ignition are not reached again. Indeed, as explained in the previous section, the new dust particle generation appears in a void region surrounded by dust particles from the previous generation. The new dust particle formation thus starts in a different plasma environment as attested by the electrical measurement that contains information integrated over the whole discharge. The void opening that allows the new formation process can be roughly localized in Fig. 3 around $25 \mathrm{~s}$. It corresponds to a situation where dust particles are progressively (but not totally) expelled from the plasma center. During this opening, and before the new grown dust particles start to significantly affect the plasma, an important loss of charged dust particles is induced, freeing some electrons. It partially explains the increase of the current amplitude that is proportional to the free electron density. This increase can also be due to a simultaneous enhancement of the ionization inside the void as observed in [16]. Then, the growth of a new generation starts. The exact moment is quite difficult to localize with only these diagnostics because a constant competition exists between the losses and the formation of charged dust particles. Nevertheless, there is a slight change in the signal slope around $60 \mathrm{~s}$ that can roughly indicate this instant. 
When the formation overcomes the losses, the electron density decreases again. The current does not decrease to its minimum value (the one that follows the first generation). Indeed, the first generation was trapped and able to grow (and thus to get more charged), while in the present situation the constant growth of a new generation expels partly the older dust particles. In some cases, it has been reported that these oscillations related to successive generations reproduce the evolution of the first generation [41]. In these conditions, the growth of a new generation starts only when the previous generation has been completely expelled from the discharge. It can be related to the fact that dust particle growth conditions are not fulfilled while the previous dust particle generation is still in the discharge. Another possibility is that the typical duration of the growth cycle is of the same order of magnitude than the time needed to expel dust particles under the action of various forces.

\section{SUCCESSIVE GENERATION INSTABILITIES}

Dust successive generations are characterized by low-frequency oscillations in the signals as observed in Fig. 3. But it appears that a higher-frequency component is superimposed on this slowly evolving signal [36]. This component is well emphasized by performing a time-resolved Fourier analysis (spectrogram) of the signal shown in Fig. 3. This analysis is shown in Fig. 4 where the time scale has been limited to the second and third dust particle generations. It appears that clearly detectable instabilities arise from around $40 \mathrm{~s}$. It means, by comparison with Fig. 3, that they occur a few seconds after the void opening around $25 \mathrm{~s}$. After a short setting up phase of the instability around $50 \mathrm{~s}$, two alternating regimes can be observed, a highly and a less ordered one (HOR and LOR) with typical frequencies of a few tens of Hz. The HOR is characterized by prevailing frequencies as observed in the spectrogram (using the given color bar in linear scale, they correspond to pixels with colors that tend toward red). The first two HORs related to the second and third dust particle generations are indicated by arrows in Fig. 4. Their duration is about $30 \mathrm{~s}$ and during this time, a slight decrease (of about $5 \mathrm{~Hz}$ ) of their main frequency is observed. The LOR is located in between the HORs and corresponds to a signal that is still oscillating but with less defined frequencies in a slightly more chaotic way.

By using Figs. 3 and 4, it appears that the first HOR starts around $60 \mathrm{~s}$, which corresponds to the slight change in the slope of the electrical measurement. If we assume that the void starts its opening around $25 \mathrm{~s}$, it can be considered that between 25 and $60 \mathrm{~s}$ dust particles from the previous generation are expelled. This new dust-free space allows the formation of a new dust particle generation. The time corresponding to the birth of this generation is not easy to determine. However, the change in the signal slope around $60 \mathrm{~s}$ indicates that dust particle formation has been initiated in the void. As these dust particles grow, they get more charged and start to compensate the partial loss of dust particles from the previous generation, inducing the slight change in the current slope. In Fig. 4, this instant ( $60 \mathrm{~s})$ corresponds to the beginning of the HOR. When this charged population overcomes the losses, a decrease in the signal of Fig. 3 is observed and corresponds to the LOR in Fig. 4. Then this cycle reproduces itself.

It is known that the void is a particular region where many self-excited unstable phenomena can take place $[42,43,45,47]$. In the PKE-Nefedov reactor, one of these unstable regimes corresponds to a low-frequency oscillation of the void size triggered by the growth of a new generation inside [48]. Even if it also corresponds to void size oscillations, this phenomenon is different from the more well-known heartbeat instability $[42,43,45,47]$, which has slightly higher frequencies and which is not triggered by any dust formation inside the void. A similar effect can take place in the silane reactor. In this case, the observed HOR corresponds to void size oscillations induced by the growth of new dust particles inside the void. It is consistent with the apparition time of the HOR, a few seconds after the void opening, and with the change in the curve slope (Fig. 3) attesting dust formation. 


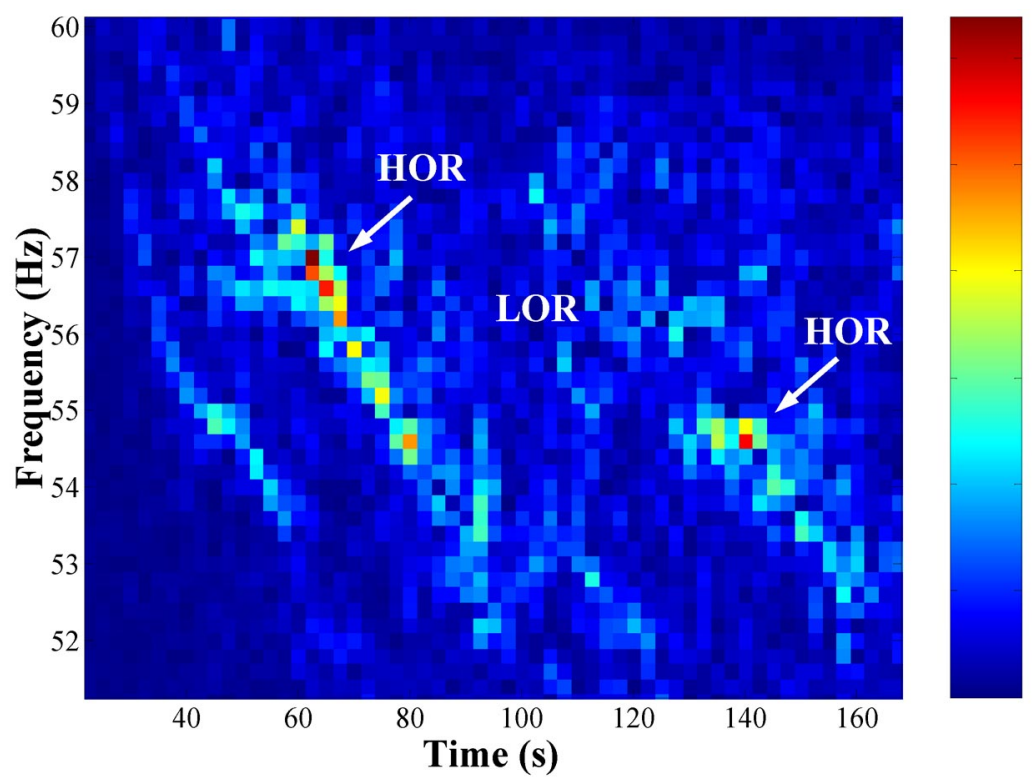

Fig. 4 Spectrogram of Fig. 3 around the second and third dust particle generations. It underlines that an oscillating pattern of a few tens of $\mathrm{Hz}$ is superimposed on the continuous signal variation. Two alternating regimes can be identified, HOR and LOR.

\section{POLYDISPERSE CLOUD: FROM PLASMA TO DEPOSITED LAYER}

Situations where several generations of dust particles coexist in the same cloud need to be well detected. Indeed, for any application requiring only one dust particle population (with a narrow size distribution), dust clouds constituted of several generations have to be avoided. It seems logical that the complex structure of the levitating dust cloud will be transferred to the deposited layer. This effect is clearly observed in Fig. 5, corresponding to a deposition performed in the silane reactor and analyzed by scanning electron microscopy (SEM). Dust particles coming from several generations can be easily identified. For this experiment, the plasma has been switched off during the third dust particle generation detected thanks to the electrical measurements. A more precise analysis with a different magnification also shows that the background film is composed of nanoparticles of a few nanometers embedded in amorphous silicon continuously deposited [49].

Some particular features are observed in Fig. 5, such as the presence of dark regions that appear to be holes in the film [49]. Two holes with different sizes are marked with a solid arrow in Fig. 5. These holes correspond to places from where big dust particles have been removed. Indeed, the experimental procedure to perform this ex situ analysis is the following: first, a silicon substrate has been placed on the lower grounded electrode, then the deposition has been performed, and finally the reactor has been vented to atmospheric pressure in order to collect the substrate for SEM. If this venting is performed too abruptly, dust particles that have a low sticking coefficient and/or are not completely buried in the film can be removed or just slightly moved. Obviously, this effect is more effective on big dust particles, but smaller holes can also be observed (bottom arrow in Fig. 5). As mentioned, some dust particles are just slightly moved, as can be observed in Fig. 5 at the place indicated by a dotted arrow. The big dust particle moved very little and reveals partly the underlying hole. These holes have an unexpected interesting consequence. They give access to the history of the deposition as they reveal the inner structure of the deposited film [49]. The two conclusions that can be drawn from Fig. 5 are the following: first, the venting of the reactor has to be performed carefully in order to prevent altering of the de- 


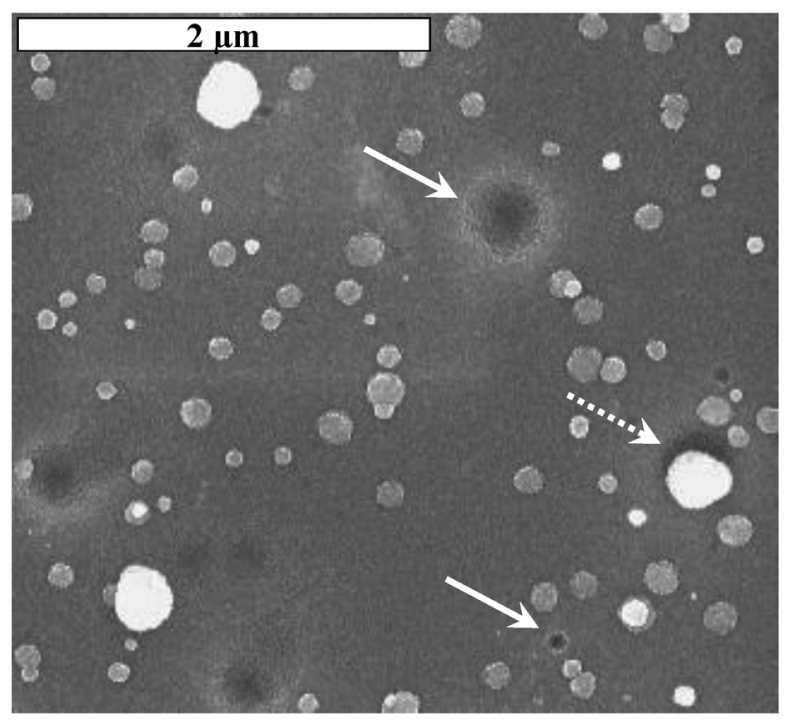

Fig. 5 SEM image of a deposition performed after successive generations of dust particles have been formed in the plasma phase. Dust particles of various sizes are observed, and some holes have been revealed by dust particle displacements.

posited layer and avoid moving structures with low sticking coefficient, secondly, holes can be useful to easily access the film structure.

\section{CONCLUSIONS}

In this paper, the way successive generations of dust particles are succeeding one after the other has been addressed. It has been shown that this process needs the temporary occurrence of dust-free regions where conditions for new dust particle formation are fulfilled. The void is directly involved in this cyclic process and is the place where new dust particles can grow. Several diagnostics can give indications on the evolution of this phenomenon. It usually corresponds to a very low frequency oscillation of the measured signals. The main difficulty lies in the signal interpretation due to a constant competition between the growth of the new generation and the expulsion of the old one. Correlation between several diagnostics is then recommended.

In addition to this slow evolution of the signal, some higher-frequency instabilities can be present. They seem to be related to specific void size oscillations triggered by the growth of the new generation inside. They show two distinct regimes that can be distinguished by their main frequencies that are of the same order of magnitude but more or less well defined.

The last aspect that has been pointed out is related to the deposition that can be obtained when a cloud containing multiple dust particle generations is trapped in the discharge. The complex structure of the cloud is transferred to the deposited layer consisting of a mixture of dust particles with different sizes. A particular behavior has been underlined, consisting of dust particle moves due to a too violent venting of the vacuum chamber. Dust particles that moved can let at their original position a hole, giving access to the inner structure of the deposited film.

\section{ACKNOWLEDGMENTS}

The authors would like to thank S. Dozias and B. Dumax for electronic support and J. Mathias for optical support. The PKE-Nefedov chamber has been made available by the Max-Planck-Institute for 
Extraterrestrial Physics, Germany, under the funding of DLR/BMBF under grant No. 50WM9852. This work was supported by CNES under contract 02/CNES/4800000059.

\section{REFERENCES}

1. P. K. Shukla, A. A. Mamun. Introduction to Dusty Plasma Physics, IOP Publishing, Bristol (2002).

2. C. K. Goertz. Rev. Geophys. 27, 271 (1989).

3. E. Kovačević, I. Stefanović, J. Berndt, Y. J. Pendleton, J. Winter. Astrophys. J. 623, 242 (2005).

4. C. Szopa, G. Cernogora, L. Boufendi, J. J. Correia, P. Coll. Planet. Space Sci. 54, 394 (2006).

5. R. M. Roth, K. G. Spears, G. D. Stein, G. Wong. Appl. Phys. Lett. 46, 253 (1985).

6. G. S. Selwyn, J. Singh, R. S. Bennett. J. Vac. Sci. Technol. A 7, 2758 (1989).

7. L. Boufendi, A. Bouchoule. Plasma Sources Sci. Technol. 11, A211 (2002).

8. J. Winter. Plasma Phys. Control. Fusion 46, B583 (2004).

9. D. L. Rudakov, J. H. Yu, J. A. Boedo, E. M. Hollmann, S. I. Krasheninnikov, R. A. Moyer, S. H. Muller, A. Yu. Pigarov, M. Rosenberg, R. D. Smirnov, W. P. West, R. L. Boivin, B. D. Bray, N. H. Brooks, A. W. Hyatt, C. P. C. Wong, A. L. Roquemore, C. H. Skinner, W. M. Solomon, S. Ratynskaia, M. E. Fenstermacher, M. Groth, C. J. Lasnier, A. G. McLean, P. C. Stangeby. Rev. Sci. Instrum. 79, 10F303 (2008).

10. C. Arnas, A. Mouberi, K. Hassouni, A. Michau, G. Lombardi, X. Bonnin, F. Bénédic, B. Pégourié. J. Nucl. Mater. 390-391, 140 (2009).

11. J. Berndt, E. Kovačević, I. Stefanović, O. Stepanović, S. H. Hong, L. Boufendi, J. Winter. Contrib. Plasma Phys. 49, 107 (2009).

12. Y. Watanabe, M. Shiratani, Y. Kubo, I. Ogawa, S. Ogi. Appl. Phys. Lett. 53, 1263 (1988).

13. A. A. Howling, C. Hollenstein, P. J. Paris. Appl. Phys. Lett. 59, 1409 (1991).

14. A. Bouchoule, L. Boufendi, J. Hermann, A. Plain, T. Hbid, G. Kroesen, E. Stoffels, W. W. Stoffels. Pure Appl. Chem. 68, 1121 (1996).

15. U. V. Bhandarkar, M. T. Swihart, S. L. Girshick, U. R. Kortshagen. J. Phys. D: Appl. Phys. 33, 2731 (2000).

16. M. Cavarroc, M. Mikikian, Y. Tessier, L. Boufendi. Phys. Rev. Lett. 100, 045001 (2008).

17. C. Deschenaux, A. Affolter, D. Magni, C. Hollenstein, P. Fayet. J. Phys. D: Appl. Phys. 32, 1876 (1999).

18. S. Hong, J. Berndt, J. Winter. Plasma Sources Sci. Technol. 12, 46 (2003).

19. J. Pereira, V. Massereau-Guilbaud, I. Géraud-Grenier, A. Plain. J. Appl. Phys. 103, 033301 (2008).

20. K. De Bleecker, A. Bogaerts, W. Goedheer. Phys. Rev. E 73, 026405 (2006).

21. E. Kovačević, J. Berndt, I. Stefanović, H. W. Becker, C. Godde, T. Strunskus, J. Winter, L. Boufendi. J. Appl. Phys. 105, 104910 (2009).

22. G. M. Jellum, D. B. Graves. J. Appl. Phys. 67, 6490 (1990).

23. B. Ganguly, A. Garscadden, J. Williams, P. Haaland. J. Vac. Sci. Technol. A 11, 1119 (1993).

24. G. Praburam, J. Goree. Phys. Plasmas 3, 1212 (1996).

25. M. Mikikian, L. Boufendi, A. Bouchoule, H. M. Thomas, G. E. Morfill, A. P. Nefedov, V. E. Fortov, and the PKE-Nefedov Team. New J. Phys. 5, 19 (2003).

26. C. Arnas, A. A. Mouberi. J. Appl. Phys. 105, 063301 (2009).

27. J. Schauer, S. Hong, J. Winter. Plasma Sources Sci. Technol. 13, 636 (2004).

28. E. V. Johnson, Y. Djeridane, A. Abramov, P. Roca i Cabarrocas. Plasma Sources Sci. Technol. 17, 035029 (2008).

29. L. Ravi, S. L. Girshick. Phys. Rev. E 79, 026408 (2009).

30. B. Walch, M. Horanyi, S. Robertson. IEEE Trans. Plasma Sci. 22, 97 (1994).

31. A. Melzer, T. Trottenberg, A. Piel. Phys. Lett. A 191, 301 (1994).

(C) 2010, IUPAC

Pure Appl. Chem., Vol. 82, No. 6, pp. 1273-1282, 2010 
32. C. Arnas, M. Mikikian, F. Doveil. Phys. Scr. T89, 163 (2001).

33. L. Couëdel, A. A. Samarian, M. Mikikian, L. Boufendi. Europhys. Lett. 84, 35002 (2008).

34. L. Couëdel, A. Mezeghrane, A. A. Samarian, M. Mikikian, Y. Tessier, M. Cavarroc, L. Boufendi. Contrib. Plasma Phys. 49, 235 (2009).

35. M. Cavarroc, M. C. Jouanny, K. Radouane, M. Mikikian, L. Boufendi. J. Appl. Phys. 99, 064301 (2006).

36. M. Cavarroc, M. Mikikian, Y. Tessier, L. Boufendi. Phys. Plasmas 15, 103704 (2008).

37. M. Mikikian, M. Cavarroc, L. Couëdel, L. Boufendi. Phys. Plasmas 13, 092103 (2006).

38. M. Mikikian, L. Couëdel, M. Cavarroc, Y. Tessier, L. Boufendi. IEEE Trans. Plasma Sci. 36, 1012 (2008).

39. M. Cavarroc, M. Mikikian, G. Perrier, L. Boufendi. Appl. Phys. Lett. 89, 013107 (2006).

40. U. Kortshagen. J. Phys. D: Appl. Phys. 42, 113001 (2009).

41. J. Berndt, S. Hong, E. Kovačević, I. Stefanović, J. Winter. Vacuum 71, 377 (2003).

42. J. Goree, G. E. Morfill, V. N. Tsytovich, S. V. Vladimirov. Phys. Rev. E 59, 7055 (1999).

43. M. Mikikian, L. Couëdel, M. Cavarroc, Y. Tessier, L. Boufendi. New J. Phys. 9, 268 (2007).

44. L. Couëdel, A. A. Samarian, M. Mikikian, L. Boufendi. IEEE Trans. Plasma Sci. 36, 1014 (2008).

45. M. Mikikian, M. Cavarroc, L. Couëdel, Y. Tessier, L. Boufendi. Phys. Rev. Lett. 100, 225005 (2008).

46. A. Melzer, A. Homann, A. Piel, V. A. Schweigert, I. V. Schweigert. AIP Conf. Proc. 446, American Institute of Physics, New York, 168 (1998).

47. M. Mikikian, L. Boufendi. Phys. Plasmas 11, 3733 (2004).

48. M. Mikikian, L. Boufendi, A. Bouchoule. Proc. $30^{\text {th }}$ EPS Conf. on Contr. Fusion and Plasma Phys., St. Petersburg, R. Koch, S. Lebedev (Eds.), European Physical Society, Petit-Lancy, ECA 27A, O-3.1B (2003).

49. M. Cavarroc, M. Mikikian, Y. Tessier, L. Boufendi. IEEE Trans. Plasma Sci. 36, 1016 (2008). 